\title{
OS PRINCÍPIOS CONSTITUCIONAIS DO DIREITO DE FAMÍLIA
}

\author{
Luciane Faraco $^{1}$
}

\section{INTRODUÇÃO}

Os ordenamentos jurídicos modernos não comportam a concepção do Direito como uma estrutura formal que identifica o indivíduo como um sujeito abstrato responsável apenas por impulsionar o nascimento da norma e que faz parte desta, unicamente, porque identificado na figura do contratante, do marido, do usufrutuário dentre outras.

O Direito hoje atenta ao indivíduo e aos fatos situações jurídicas que impõem o surgimento ou a adequação da norma para dar resposta ao sujeito detentor do direito. O ser humano importa mais que o objeto, este é o processo da Constitucionalização do Direito Civil.

No percorrer deste caminho, observou-se a carência do positivismo como hermenêutica jurídica ao se constatar que o sistema de regras diante dessa nova visão do direito ao indivíduo como fundamento da República, expresso no art. $1^{\circ}$, inc. III da Constituição Federal, mingou por insuficiência de regras para aplicação em inéditas, mas não isoladas, circunstâncias jurídicas.

A jurisprudência tornou-se, assim, relevante fonte do Direito passando a responder por decisões a fatos

1 Advogada; sócia do escritório Limongi Faraco Ferreira Advogados; inventariante dativa e curadora da $6^{\text {a }}$ Vara de Família e Sucessões de Porto Alegre; especialista em Direito Civil Aplicado; pós-graduada pela Associação dos Juízes do Rio Grande do Sul (AJURIS). 
sem suporte normativo. No trânsito das fontes do direito, a fundamentação das decisões socorria-se cada vez mais aos princípios jurídicos e assim a jurisprudência os aplicava diretamente no caso concreto.

O Estatuto da Mulher Casada (Lei $\mathrm{n}^{\circ} 4.121 / 1962$ ), alavancou a libertação da esposa. A aprovação da Lei do Divórcio no Brasil (Lei ${ }^{\circ}$ 6.515), em 1977, após várias tentativas frustradas primordialmente em razão das forças religiosas em contrário, sobrepôs o princípio basilar do direito à liberdade ao da indissociabilidade do vínculo matrimonial. Assim, timidamente, o ordenamento legislativo pátrio respondia aos novos fatos.

Em nível internacional, o marco para valoração do indivíduo como ente maior a ser protegido, revelou-se, em 1959, com a Declaração Universal dos Direitos da Criança, que impunha o reconhecimento da criança e do adolescente como membros da família com interesses próprios a serem observados e tutelados.

Esse cenário era o de uma sociedade em movimento, expressivamente acelerado, ao ponto de impor uma mudança. As normas existentes eram insuficientes ao abrigo de fatos cada vez mais diversos, e não mais particulares e isolados, que espelhavam uma nova realidade clamando por um amparo legal.

A Constituição Federal de 1988 veio, assim, a consagrar dentre seus princípios fundamentais, o da dignidade da pessoa humana e, para o ordenamento jurídico pátrio, especialmente para o Direito de Família, isso é absolutamente relevante. Daí em diante, todo ordenamento jurídico, legal e hermenêutico passaram a dar ao indivíduo a condição de destinatário principal da proteção normativa independentemente do seu papel social.

A partir de então, o Direito de Família com zelo ao espírito e aos princípios constitucionais, em especial da dignidade da pessoa humana (art. $1^{\circ}$, inc. III da Constituição Federal), adotou nova e legítima postura perante antigas questões como filiação "ilegítima", casamento como única forma de constituição da família e patriarcalismo.

Os princípios aludidos como fonte do direito na Lei de Introdução ao Código Civil (Decreto 4.657, de 4 de setembro de 1942), insertos então na Constituição da República como fundamentais e aliados à evolução do pensamento científico, impactaram nosso ordenamento jurídico, oportunizando resposta aos fatos que antes vinham desamparados.

Nesse sentido, impulsionaram o aparecimento de leis específicas ao menor (Estatuto da Criança e do Adolescente), a regulação do art. $226, \S 3^{\circ}$ da Constituição Federal (Lei no 9.278 de 1996) pertinente à união estável e ao direito dos companheiros aos alimentos e à sucessão (Lei ${ }^{\circ} 8.971$ de 
1994), para citar algumas. Sob esse novo espírito pós-positivismo entra em vigor o Código Civil, em 2002, e, após este, o Estatuto do Idoso (Lei $\mathrm{n}^{\mathrm{o}} 10.741$ de $1^{\circ}$ de outubro de 2003), a Lei Maria da Penha ( $\mathrm{n}^{\circ} 11.340$ de 7 de agosto de 2006) e, por último, o Estatuto da Juventude (Lei $\mathrm{n}^{\circ} 12.852$, de 5 de agosto de 2013), para destacar algumas.

A Constituição Federal de 1988 foi o marco legislativo de inserção no ordenamento jurídico pátrio dos princípios, dispondo de forma expressa os que norteiam toda nossa estrutura social e jurídica porque se prestam ao reconhecimento de valores sedimentados.

Assim, o Direito de Família passou a se reger por novos princípios contemporizados com valores enraizados e consagrados que oportunizam, nesse novo sistema, o abrigo legislativo às novas situações jurídicas que se revelam, desde o reconhecimento de estruturas familiares diversas até variadas formas de alcance ao estado de filiação.

A reflexão que se propõe, dos Princípios Constitucionais do Direito de Família, visa contribuir para o árduo trabalho que aos operadores do Direito recai para dispor à sociedade na composição de seus conflitos fami- liares essa nova hermenêutica que não mais se restringe às regras existentes, deixando ao relento o que ali não está, pois, princípios e valores abrigam a todos e se prestam ao alcance de qualquer indivíduo em qualquer situação jurídica.

\section{OS PRINCÍPIOS COMO FONTE DO DIREITO DE FAMÍLIA}

\section{A) No Contexto do Direito Contemporâneo}

Partindo-se da divisão apresentada por René David² em sua obra Os grandes Sistemas do direito contemporâneo, o panorama mundial identifica a família romano-germânica, família common law, família dos direitos socialistas, direitos muçulmanos, hindu, judaico do Extremo Oriente, da África negra e de Madagascar. O jurista francês conclui pela influência dos sistemas políticos e econômicos que esses modelos de família, enquanto sistemas jurídicos, sofrem, e destaca, ainda, a globalização como outro fato contaminador a esses.

Face isso, considera-se hoje a proximidade dos sistemas da família romano-germânica com a família com-

2 DAVID, René. Os grandes sistemas do direito contemporâneo. Trad.de Hermínio A. Carvalho. São Paulo: Martins Fontes, 2002. 
mon law, que se uniram num primeiro momento pela vértice religiosa cristã e, posteriormente, pelas mudanças políticas e econômicas que também caminharam para sentido comum.

Essa aproximação de sistemas é uma tendência natural, pela proximidade dos povos e abertura das estruturas políticas, e o que disso decorre, e interessa, é o consequente enfraquecimento do sistema codificado, a ascensão dos microssistemas normativos e o novo status que se emprega às fontes do direito, em particular aos princípios.

Ante isso, o estreitamento da estrutura familiar romano-germânica com a família common law, em franca e enriquecedora unificação, oportunizou a harmônica composição de uma estrutura mista, fruto de dois sistemas. A respeito desse fenômeno René David conclui:

[...] common law conserva hoje a sua estrutura, muito diferente da dos direitos romano-germânicos, mas o papel desempenhado pela lei foi aí aumentado e os métodos nos dois sistemas tendem a aproximar-se; sobretudo a regra do direito tende, cada vez mais, a ser concebida nos países do common law como ocorre nos países da família romanogermânica. Quanto à substância, soluções muito próximas, inspiradas por uma mesma ideia de Justiça, são muitas vezes dadas às questões pelo direito nas duas famílias de direito.

René, adiante, afirma a tendência de se falar no direito ocidental em uma única família arrolando alguns países em que esta composição mista já pode ser identificada, na Escócia, em Israel, na África do Sul, Filipinas e Província de Quebec.

Isso tudo revela o quanto o Direito, em especial o Direito de Família, está cada vez mais próximo, ou sensível, à construção de decisões judiciais com suporte extremamente primordial em princípios, que, carregados de subjetividade inerente à construção desses e, ainda, pela louvável utilização de ciências multidisciplinares, como a psicanálise, aproximam essas decisões de um ideal de justiça e equidade. Não há outro ramo do direito que mais prescinda das ciências que estudam o ser humano, do que o direito de família.

É nesse sentir que as palavras de Rodrigo da Cunha Pereira ${ }^{3}$ se destacam:

Das conhecidas e tradicionais fontes do Direito Positivo - a lei, jurisprudência, doutrina, os costumes, a equidade, o direito comparado, a analogia e os princípios gerais - interessa-nos aqui destacar, para melhor compreen-

3 PEREIRA, Rodrigo da Cunha. Princípios fundamentais e norteadores do direito de família. São Paulo: Editora Saraiva, 2012, p. 42. 
der e viabilizar uma aplicação prática, os princípios gerais do direito, especialmente para estabelecer princípios norteadores para o Direito de Família. É essa fonte do Direito que faz tornar inaceitável para o jurista uma decisão Judicial, ou uma solução no plano social que não seja justa e não esteja de acordo com a equidade. [...] Com a evolução e o desenvolvimento de um direito civil constitucional, os princípios ganharam uma força normativa muito maior e, consequentemente, perderam seu caráter de mera supletividade, como anunciado nos textos legislativos acima transcritos. É equivocada a ideia e o pensamento de que os princípios vêm por último no ato interpretativo integrativo. Ao contrário, os princípios, como normas que são, vêm em primeiro lugar e são a porta de entrada para qualquer leitura interpretativa do Direito.

Os princípios gerais do direito, na estrutura normativa brasileira, estão previstos na Lei de Introdução ao Código Civil (Decreto-Lei 4.657, de 4 de setembro de 1942), que dispõe e consagra o rol das fontes do direito reconhecidas em nosso sistema legal e, inclusive, o faz de forma hierárquica, como se observa em seus $\operatorname{artigos} 4^{\circ}$ e $5^{\circ}$ :

Art. $4^{\circ}$. Quando a lei for omissa, o juiz decidirá o caso de acordo com a analogia, os costumes e os princípios gerais de direito.

Art. $5^{\circ}$. Na aplicação da lei, o juiz atenderá aos fins sociais a que ela se dirige e às exigências do bem comum.

Da mesma forma assim faz o Código de Processo Civil através do art. 126:

Art. 126. O juiz não se exime de sentenciar ou despachar alegando lacuna ou obscuridade da lei. No julgamento da lide caber-lhe-á aplicar as normas legais; não as havendo, recorrerá à analogia, aos costumes e aos princípios gerais de direito.

A inserção dos princípios gerais do direito, seja na forma abstrata e subjetiva, seja de forma expressa na legislação, tanto no Brasil como na legislação de todo e qualquer Estado Democrático de Direito, não é, portanto, novidade, muito pelo contrário.

O que o direito contemporâneo traz de novo é a valoração dos princípios, não apenas como fonte do direito, como um suporte interpretativo à norma, mas, sim, o seu reconhecimento até como norma, em coro à reflexão de Robert Alexy ${ }^{4}$ que parte do pressuposto de que princípios e regras são espécies do gênero norma, pelo fato de que ambos dizem o que "deve ser". 


\section{B) Na Constituição Federal:}

A carga principiológica da Constituição Federal de 1988 foi, com certeza, um marco absolutamente distinto e positivo do Direito Brasileiro. Foi a partir daí que o sistema legislativo pátrio passou a ser sustentado, acompanhando a tendência jurídica ocidental, por uma hermenêutica constitucional que agrega regras e princípios a serem observados por todas demais disposições legais. E assim foi, para o Direito de Família, em especial o Código Civil e as leis afetas a esse ramo. É fruto, então, dessa realidade normativa constitucional, a nova ordem civil, a do Direito Civil-Constitucional.

O Título I da Constituição Federal, Dos princípios Fundamentais, é composto por quatro artigos, no art. $1^{\circ}$, inc. III consta o princípio da dignidade da pessoa humana, no art. $3^{\circ}$, inc. I o princípio da solidariedade. Estes dois princípios inauguram o texto constitucional e carregam não apenas para este, mas para todo repertório normativo brasileiro, o cunho imperativo que têm e que, como dito na introdução, faz com que o indivíduo seja, para todo fim, o sujeito para quem a norma deve ser feita, a quem a norma deve proteger e isso deve ser observado em toda e qualquer decisão judicial ou no plano social.

A Constituição consagra o princípio da igualdade e do respeito às diferenças, respectivamente, nos artigos $3^{\circ}$, inc. IV e $5^{\circ}$ caput, e o da autonomia e da menor intervenção estatal (artigos $3^{\circ}$, inc. I; $4^{\circ}$, incisos III e IV; e $5^{\circ}$, caput).

Esses princípios são identificados de forma absolutamente direta, pois expressos de plano no preâmbulo Constitucional, inclusive, sob o título de "princípios fundamentais". Ao longo do texto, porém, outros despontam de forma também expressa, porém, não com identificação imediata como um princípio, porque insertos no corpo de uma norma específica, como, por exemplo, o da paternidade responsável identificado direta e expressamente no art. $226, \S 7^{\circ}$.

Rodrigo da Cunha Pereira ${ }^{5}$ (2012, p. 58), sempre lembrado e invocado por sua mestria ao discorrer sobre o tema (Princípios Fundamentais nortea- dores do Direito de Família) aponta, além dos princípios acima, o princípio do melhor interesse da criança e do adolescente (art. 227), da pluralidade de formas de família (art. 226, $\S 4^{\circ}$ ), da paternidade responsável (art. 226, $\S 7^{\circ}$, art. 227 e art. 229) e, ainda, da monogania, da afetividade e da responsabilidade.

5 Op. cit. p. 5. 


\section{OS PRINCÍPIOS CONSTITUCIONAIS NO DIREITO DE FAMÍLIA}

\section{A) O rol constitucional e sua aplicabilidade}

Está no art. $1^{\circ}$, inc. III da Constituição Federal do Princípio da Dignidade da Pessoa Humana como fundamento do Estado Democrático de Direito. É, portanto, o princípio máximo, até porque é o que melhor representa e o produto de toda a mudança da estrutura jurídica hermenêutica e legislativa, antes referida, que passou a priorizar o indivíduo como destinatário principal da lei.

A proteção dos direitos inerentes ao ser humano, em qualquer esfera legislativa é justificada, aplicada e interpretada, sempre, em atenção à dignidade da pessoa.

Ingo Wolfgan Sarlet ${ }^{6}$ conceitua dignidade da pessoa humana como:

[...] a qualidade intrínseca e distintiva de cada ser humano que o faz merecedor do mesmo respeito e consideração por parte do Estado e da comunidade, implicando, neste sentido, um complexo de direitos e deveres fundamentais que asseguram a pessoa tanto contra todo e qualquer ato de cunho degradante e desumano, como venham a the garantir as condições existenciais mínimas para uma vida saudável, além de propiciar e promover a sua participação ativa e co-responsável nos destinos da própria existência e da vida em comunhão com os demais seres humanos.

Para Sarlet, a dignidade tem um caráter normativo justamente em razão de ser, dentre os princípios da ordem constitucional, o fundamental com relação à pessoa. Afirma, ainda, que esse princípio também atua como parâmetro (tanto limitar quanto protetor) quando há colisão entre os direitos fundamentais e/ou entre princípios. É o princípio dos princípios.

O Direito de Família é o ramo do Direito Privado em que a proteção da pessoa humana mais se impõe, pois qualquer conflito por envolver pessoas ligadas por vínculos de parentesco, sanguíneo ou socioafetivo, coloca o indivíduo a mercê, no mínimo, de um abalo emocional.

Para Guilherme Calmon Nogueira da $\mathrm{Gama}^{7}$, as relações familiares passaram a ser funcionalizadas em razão da dignidade de cada integrante e, complementa:

6 SARLET, Ingo Wolfgang. Dignidade da pessoa humana e direitos fundamentais na Constituição Federal de 1998. Porto Alegre: Livraria do Advogado, 2001, p. 60.

7 DA GAMA, Guilherme Calmon Nogueira; GUERRA, Leandro dos Santos. A função social da família. Revista Brasileira de Direito de Família, n.39, dez.-jan. 2007, p. 157. 
Do princípio da dignidade da pessoa humana decorrem a despratrimonialização e a repersonalização das relações de família, substituindo-se a ênfase no tratamento das relações patrimoniais entre cônjuges, companheiros e parentes pela valorização de aspectos existenciais, procurando-se garantir, acima de tudo, o direito da personalidade de cada membro do grupamento familiar. A dignidade da pessoa humana, alçada no topo da pirâmide normativa do ordenamento jurídico brasileiro, encontra na família o solo apropriado para seu enraizamento e desenvolvimento, o que justifica a ordem constitucional no sentido de que o Estado dê especial e efetiva proteção às famílias, independentemente de sua espécie.

Não há, portanto, que apreciar qualquer situação jurídica ou conflito familiar sem atenção ao princípio que, acima de qualquer norma ou mesmo de qualquer outro princípio cuida e protege o ser humano, tanto na concepção física ou psíquica desse.

O princípio da solidariedade decorre do dever natural de cuidado, de zelo e assistência ao outro, assim, é reconhecido como um dever constitucional e civil, especialmente entre familiares. É a solidariedade, enquanto princípio que impõe à sociedade, ao Estado e a família e seus membros, através de outras normas específicas, o dever de proteção a criança, ao ido- so, ao adolescente, de proteção a entidade familiar, de assistência material e imaterial dentre outros.

A solidariedade, portanto, mesmo no âmbito particular (entre integrantes do mesmo grupo familiar) não está arraigada unicamente no material, no patrimonial, mas também está no afetivo e psicológico.

Da mesma forma, pode-se identificar no art. 226, $\S 8^{\circ}$, da Constituição Federal, ao dispor que "O Estado assegurará assistência à família na pessoa de cada um dos que a integram, criando mecanismos para coibir a violência no âmbito de suas relações". Como aponta Flávio Tartuce ${ }^{8}$, a consagração desse princípio, então, como solidariedade social, na ótica familiar, a partir do momento em que sua observância e efetivação é imposta ao Estado.

O princípio da igualdade está identificado no art. $3^{\circ}$, inc. IV da Constituição Federal que dispõe ser um objetivo fundamental da República - promover o bem de todos, sem preconceitos de origem, raça, sexo, cor, idade e quaisquer outras formas de discriminação. Esta parte final justifica o grifo (que não é original), porque transporta ao Direito de Família sua carga valorativa para o fim de respaldar, não apenas toda e qualquer norma proibitiva à discriminação, mas, também, para

8 TARTUCE, Flávio, em artigo publicado em: http:/jus.com.br/artigos/8468/novos-principios-do-direito-de-familia-brasileiro/2. 
impor a igualdade em específicas situações.

A consagração do princípio da igualdade também está expressa no art. $5^{\circ}$, caput e inc. I. Ao longo da Carta Maior, de forma específica, é, ainda, identificado este princípio quando reconhece e impõe a igualdade entre os filhos (no art. 227, $\S 6^{\circ}$ ), entre os cônjuges e companheiros (no art. 226, $\S 5^{\circ}$ ) e na gerência familiar (nos artigos $226, \S 5^{\circ}$ e $227, \S 7^{\circ}$ ). Quer dizer, todos os filhos são iguais perante a lei e não se admite tratamento desigual e discriminatório em razão do sexo do membro da entidade familiar, seja numa relação pessoal seja patrimonial.

$\mathrm{Na}$ sequência ditada pelo título anterior desponta o princípio da autonomia e da menor intervenção estatal (artigos $3^{\circ}$, inc. I; $4^{\circ}$, incisos III e IV; e $5^{\circ}$, caput).

A doutrina clássica, por maioria expressiva de doutrinadores, dentre os quais Pontes de Miranda, Orlando Gomes e Caio Mário da Silva Pereira afirma que o Direito de Família é um ramo do Direito Civil e, portanto, situado na esfera do Direito Privado. Silvio Rodrigues, jurista não menos brilhante que os demais, não corrobora com esse entendimento.

Hoje, essa questão é retomada porque, como se reconhece o interesse prevalecente da sociedade e do Estado na proteção da família, as normas constitucionais e infraconstitucionais impõe a estes o dever de proteção por disposições diversas; tendo, o problema acerca do limite de intervenção do público no privado em questão, novo contorno.

A questão avança para contraposição do princípio da menor intervenção estatal e o da autonomia da vontade, que para maior parte da doutrina, está presente no Direito de Família não apenas como limitador daquele, mas também como intrínseco às relações familiares.

Indagações acerca do quanto a intervenção estatal opera, de forma excessiva ou não, ao legislar regulamentando a união estável, ao dispor sobre a imputação da culpa para o fim do casamento, ou sobre a irrenunciabilidade do direito aos alimentos entre os cônjuges, para citar alguns exemplos, é o que demonstra a relevante análise e ponderação desse princípio constitucional.

Não haveria em situações como as exemplificadas acima, eventual excesso intervencionista, inclusive com invasão à autonomia da vontade? É a autonomia da vontade um princípio do direito de família ou seria este apenas afeto ao direito das obrigações?

Rodrigo da Cunha Pereira ${ }^{9}$ ( $p$. 189) ao discorrer sobre o princípio em vogue conclui:

9 Op. cit., p. 5. 
O desafio fundamental para a família e das nas normas que a disciplinam é conseguir conciliar o direito à autonomia e à liberdade de escolha com os interesses de ordem pública que se consubstanciam na atuação do Estado apenas como protetor. Essa conciliação deve ser feita por meio de uma hermenêutica comprometida com os princípios fundamentais do Direito de Família, especialmente o da autonomia privada, desconsiderando tudo aquilo que põe o sujeito em posição de indignidade e o assujeite ao objeto da relação ou ao gosto de outrem sem o seu consentimento.

Da Cunha Pereira destaca, ao final, que a Emenda Constitucional n. 66, de 13.7.2010, ao abolir o prazo para requerer o divórcio reforçou o princípio da intervenção mínima do Estado.

Adentrando nos artigos constitucionais do Capítulo VII, Da Família, da Criança, do Adolescente, do Jovem e do Idoso, identificam-se os princípios do melhor interesse da criança e do adolescente (no art. 227), da pluralidade de formas de família (art. 226, $\S 4^{\circ}$ ), da paternidade responsável (art. 226, $\S 7^{\circ}$, art. 227 e art. 229) e da monogania, da afetividade e da responsabilidade.

$\mathrm{O}$ artigo 227, essencialmente, abriga o princípio do melhor interesse da criança e do adolescente e, para tanto, arrola inúmeros deveres à família, à sociedade e ao Estado que compreendem propiciar à criança e ao adolescente um desenvolvimento digno, obrigando a todos em razão da especial atenção e proteção que merecem por estarem, ainda, em formação e consequente dependência integral para seu desenvolvimento.

É certo que, a aplicação desse princípio de forma direta e específica mostra-se não menos relevante no caso concreto, como, por exemplo, num conflito cujo escopo é a regulamentação da guarda da criança.

O reconhecimento da união estável e da família monoparental, como entidades familiares, que veio a ser consagrado pela Constituição Federal através do $\S 4^{\circ}$ do art. 226 abriga ao princípio da pluralidade das formas de família. A discussão que a partir de então tomou expressão doutrinária é se as entidades familiares protegidas pela Carta Maior se limitam as ali referidas ou não. Os Tribunais Pátrios tendem a, com suporte ao princípio da dignidade, estender o rol e reconhecer outras formas de entidade familiar além das duas arroladas.

O art. 226, §7 da Constituição Federal faz alusão direta e expressa ao princípio da paternidade responsável. No dizer de Guilherme Calmon Nogueira da Gama ${ }^{9}$ (2007, p. 158):

O princípio da paternidade responsável se expressa através do direito ao

10 Op. cit., p. 9. 
planejamento familiar e da obrigação dos pais de respeitar, educar, criar e auxiliar material e imaterialmente os filhos. Como já foi registrado, há responsabilidade individual e social das pessoas do homem e da mulher que, no exercício de suas liberdades ínsitas à sexualidade e à procriação, podem gerar uma nova pessoa humana cujos bem-estar físico, psíquico, espiritual e vida devem ser priorizados em consonância com os direitos fundamentais reconhecidos em seu valor.

O exercício, portanto, da paternidade responsável tem seu início no exercício livre à sexualidade e à procriação, no entanto, uma vez gerada a pessoa humana, o indivíduo por esta responsável deverá, pela condição de genitor, atentar aos direitos desse ser humano e, para tanto, atender as disposições contidas nos artigos 227 e 229 da Carta Maior.

A aplicabilidade desse princípio, no caso concreto, se revela no não acolhimento do desemprego como justificativa para fins de elidir o executado do cumprimento da obrigação alimentar, em sede de execução de alimentos, pois se o mesmo encontra dificuldade em sua mantença ele, pelo menos, é detentor de capacidade laboral e por isso, está ao seu alcance a mantença do filho que, ao contrário, depende integralmente dele e não detém esta capacidade em razão de sua idade.

\section{B) A monogamia, a afetividade e a função social enquanto princípios "não expressos"}

Nosso texto constitucional, conforme demonstrado nos títulos anteriores, é extremamente rico ao dispor de forma expressa acerca dos princípios que abrigam, a partir de sua promulgação, o Direito de Família.

A resposta ao fato, à nova realidade que se moldou, e que num ritmo cada vez mais acelerado altera seus moldes, veio, com muito brilhantismo, recepcionada na Constituição $\mathrm{Fe}$ deral de 1988.

O fato se impõe ao Direito e é em razão dele que se criam ou se modificam as leis. A par desta uníssona afirmação, há de se reconhecer que o fato para assim o fazer deve conter uma carga de aceitação (democrática) da sociedade que o reconhece e aceita porque não afronta princípios subjetivos norteadores da sociedade.

Esses princípios carecem de recepção expressa explícita no texto normativo, pois estão compreendidos de forma absolutamente inerente, simbiótica na sociedade decorrente de um consenso entre os indivíduos que a integram.

Rodrigo da Cunha Pereira ${ }^{11}$ (2012, p. 19), quanto aos princípios não expressos ao invocar Noberto Bobbio destaca:

11 Op. cit., p. 5. 
Os princípios gerais não expressos são aqueles que estão contidos e subentendidos no texto legal, ou melhor, são aqueles que se podem tirar por abstração de normas específicas ou, pelo menos, não muito gerais: são princípios, ou normas generalíssimas, formulados pelo intérprete, que busca colher, comparando normas aparentemente diversas entre si, aquilo a que comumente se chama o espírito do sistema.

Adiante, o autor, ao apontar esses princípios insertos em nosso ordenamento jurídico, reporta-se à moralidade pública no Direito Administrativo e à monogania no Direito de Família que diz ser um princípio não expresso, que paira sobre todos os textos legislativos, ou seja, nenhuma lei poderá ir de encontro a este princípio jurídico, pois se o fizer haverá imposição de uma reorganização do sistema.

Quer dizer, a monogania é um princípio cultural e é com base nesse que estão organizadas juridicamente todas as formas de família conjugal que se identificam em nosso sistema. É, portanto, uma questão cultural e organizacional (interdito proibitivo) e não moral, como se pode, numa análise rasa, concluir.

O Código Civil ao dispor da fidelidade (art. 1.566) e da lealdade (art. 1.724) como deveres recíprocos do casamento e da união estável, assim como ao repudiar o concubinato (art. 1.727), o faz em razão do princípio da monogania.
O reconhecimento do afeto enquanto princípio norteador do Direito de Família Contemporâneo é resultado claro e absolutamente positivo da valoração primeira do indivíduo. O sentimento é impulso psicológico inerente ao ser humano, logo, o sentir afeto, o desenvolver afeto é instinto natural, não submetido a um controle racional.

$\mathrm{O}$ afeto é um sentimento positivo e, por assim ser, a sua ação e o seu desenvolvimento sempre se prestam à construção de uma relação familiar saudável, pois fruto de uma vontade intrínseca e genuinamente verdadeira de formar um vínculo, de se entrelaçar.

Todo o novo trilhar normativo atento ao indivíduo e sustentado na dignidade da pessoa humana é possível, e bem mais realizável, em razão do aporte de ciências multidisciplinares que se dedicam ao estudo do ser humano, de sua origem, de sua sociedade e de sua mente. Particularmente com relação ao afeto no Direito de Família, a psicanálise é, dentre estas disciplinas a que maior contribuição oferece.

$\mathrm{O}$ afeto aproxima e justifica o nascimento de uma relação familiar, assim como a ausência dele numa relação familiar cuja origem é unicamente sanguínea, se presta não apenas a sua desconstituição como, não raro, a inviabilizar a formação, o desenvolvimento e a vivência digna de seus membros, especialmente dos que 
se encontram mais vulneráveis dentro do núcleo familiar.

A família, enquanto instituto social e jurídico, é reconhecida e elevada à condição de base da sociedade por ter uma função essencial dentro desta. É na família que o ser humano nasce e nela se desenvolve. Se assim não for, caberá ao Estado, aos membros da sociedade e aos que por vínculo de parentes estão a esse ser ligados, a inserção deste num núcleo familiar.

Nas palavras de Guilherme Calmon Nogueira da Gama ${ }^{12}$ (2007, p. 163):

Ressalve-se, todavia, que a existência da função social de um instituto independe de sua menção expressa em texto, seja constitucional ou legal. Partindo do pressuposto de que o Direito é um produto cultural, fruto dos anseios de determinada sociedade, resulta, como óbvio, que todo instituto jurídico é criado e tem um determinado fim a cumprir.

[...]

Assim, impõe-se, atualmente, um novo tratamento jurídico da família, tratamento esse que atenda aos anseios constitucionais sobre a comunidade familiar, a qual deve ser protegida na medida em que atenda a sua função social, ou seja, na medida em que seja capaz de propiciar um lugar privilegiado para a boa vivência e dignificação de seus membros.
O irretocável status da família como base da sociedade decorre justamente do fato de ser esta o berço primeiro do ser humano que dela depende e nela se desenvolve. Assim, toda formação desse indivíduo será reflexo dos valores que receberá através e na sua família.

Flávio Tartuce ${ }^{13}(06 / 2006)$, quanto ao princípio da função social da família, afirma:

A jurisprudência, por diversas vezes, reconhece a necessidade de interpretação dos institutos privados de acordo com contexto social.

Em suma, não reconhecer função social à família e à interpretação do ramo jurídico que a estuda é como não reconhecer função social à própria sociedade.

\section{CONCLUSÃO}

A identificação dos princípios que norteiam o ordenamento jurídico brasileiro a partir do texto constitucional de forma expressa, ou não, é tarefa de profunda importância para que se chegue o mais próximo possível a decisões, especialmente, no âmbito dos conflitos familiares, justas e equânimes.

Com certeza a globalização e o rompimento de alguns sistemas po-

12 Op. cit., p. 9.

13 Op. cit., p. 11. 
líticos e econômicos se prestaram à aproximação, positiva, dos sistemas de família, em especial da common law e da romano-germânica. No entanto, a par desse fenômeno originar ou não um sistema misto, ele impõe aos operadores do direito o esforço de reestruturar e adequar a hermenêutica jurídica a esse novo cenário.

Os princípios, que se fundam no reconhecimento de um valor elevado a essa condição por seu cunho cultural, de aceitação e moldagem e, por isso, norteador da sociedade, são, por certo, das fontes do direito, a que melhor se presta para assentar os conflitos ante essa nova realidade.

A interpretação da norma a partir dos princípios, não apenas enriquece o fundamento da decisão que assenta um conflito como contribuiu para aceitação e efetivação desta. Isso, num momento social tão turvo e instável como o que hoje se enfrenta é a contribuição maior que a ciência do direito pode propiciar aos seus destinatários.

É por essa nova trilha principiológica, inclusive, que o direito responde dirimindo situações de conflitos que decorrem de fatos não mais clandestinos ou raros na sociedade, como famílias simultâneas ou uniões homoafetivas dentre outros. Os princípios, para tanto, se somam e, assim, fundamentam as decisões.

No dizer de Dimas Messias de Carvalho ${ }^{14}$ :

$\mathrm{O}$ respeito à dignidade da pessoa humana e à liberdade de planejamento da família, fundada na afeição mútua e no pluralismo, conferem aos seus membros a opção de constitui-la não apenas no casamento, e ter assegurada pelo Estado a assistência e criação de mecanismos para coibir a violência no âmbito de suas relações (art. 226, $\S 8^{\circ}, \mathrm{CF}$ ), permitindo a realização da personalidade plena dos membros da família.

Inquestionável, diante de novos conceitos e ideais da família moderna, sob a proteção dos princípios constitucionais, notadamente da liberdade, o reconhecimento da entidade familiar nas uniões homoafetivas e mesmo nas famílias simultâneas. Em consequência, deve a escolha ser respeitada e a entidade familiar receber o manto da legalidade, aplicando-se regras protetoras da união estável, permitindo aos parceiros usufruir dos benefícios proporcionados no plano da lei e na esfera das relações sociais, vedando a discriminação pela opção sexual ou modelo de família, e preservando a dignidade da pessoa humana.

O referido autor identifica, portanto, a proteção de constituições familiares diversas ou simultâneas com

14 CARVALHO, Dimas Messias de. Direito das Famílias. 3. ed. Lavras, MG: Unilavras, 2014, p. 93. 
fundamento nos princípios da dignidade da pessoa humana e da liberdade de planejamento familiar, mas isso é apenas um exemplo, pois institutos como dos alimentos compensatórios é reconhecido e aplicado em decisões correntes com suporte ao princípio da igualdade entre os cônjuges, somado ao da solidariedade.

É essa a nova estrutura interpretativa que responde aos anseios da sociedade contemporânea no que tange ao Direito de Família, que faz uso dos princípios como fonte basilar do direito pátrio, sejam os insertos na Constituição Federal, sejam os que norteiam por razão cultural intrínseca que dispensa até a forma expressa.

Sérgio Gischkow Pereira ${ }^{15}$, com sua irretocável mestria doutrinária, especialmente dedicada ao Direito de Família, foi sensível ao afirmar:
Uma família que experimente a convivência do afeto, da liberdade, da veracidade, da responsabilidade mútua haverá de gerar um grupo familiar não fechado egoisticamente em si mesmo, mas, sim, voltado para as angústias e os problemas de toda coletividade, passo relevante à correção das injustiças sociais.

O ser humano nasce e se desenvolve para viver em sociedade, para integrar e fazer parte de um grupo social. Logo, a saúde desse grupo depende da formação de cada um de seus membros e essa ocorre na família. Por isso que a composição dos conflitos familiares, an passant, pode ser vista em si mesma, porém, sua análise detalhada mostra a extensão de seus reflexos, sejam positivos ou negativos. É isso que justifica a importância e dedicação ao tema.

\section{REFERÊNCIAS}

ALEXY, Robert. Teoria de los derechos fundamentales. Tradução livre do original em espanhol. p. 83. Madrid: Centro de Estudos Políticos y Constitucionales, 2002.

ALVES, José Carlos Moreira. Direito romano. V. 1. Rio de Janeiro: Forense, 1992.
BAUMAN, Zygmunt. $O$ mal-estar da pós-modernidade. Rio de Janeiro: Jorge Zahar, 1997. p. 8-9.

BERMAN, Harold J. La formación de la tradición jurídica de occidente. México: Fondo de Cultura Económica, 1996.

15 PEREIRA, Sérgio Gischkow. Tendências modernas do direito de família. Revista dos Tribunais. São Paulo, v. 628, p. 19-39, fev. 1988. 
BOBBIO, Norberto. A Era dos Direitos. Rio de Janeiro: Nova Editora, 2004.

CARVALHO, Dimas Messias de. Direito das Famílias. Lavras, MG: Unilavras, 2014, p. 93.

CHAVES, Antonio. Tratado de direito civil. V. 1. Direito de família, 5. São Paulo: Revista dos Tribunais, 1991.

COLTRO, Antonio Carlos Mathias. A união estável: um conceito? In: ALVIN, Teresa Arruda; LAZZARINI, Alexandre Alves. (Org.) Direito de familia: aspectos constitucionais, civis e processuais. Repertório de jurisprudência e doutrina sobre direito de família, V. 3. São Paulo: Revista dos Tribunais, 1996. p. 19-44.

DA GAMA, Guilherme Calmon Nogueira; GUERRA, Leandro dos Santos. A função social da família. Revista Brasileira de Direito de Família, n. 39, dez.-jan. 2007, p. 157.

DAVID, René. Os grandes sistemas do direito contemporâneo. Trad. de Hermínio A. Carvalho. São Paulo: Martins Fontes, 2002.

GOMES, Orlando. Direito de família. 3. ed. Rio de Janeiro: Forense, 1978.

PEREIRA, Rodrigo da Cunha. Princípios fundamentais e norteadores do direito de família. São Paulo: Editora Saraiva, 2012, p. 42.

PEREIRA, Rodrigo da Cunha. Uma principiologia para o direito de família. Familia e Sucessões sob um olhar prático. Porto Alegre: IBDFAM, 2013. p. 30-45.

PEREIRA, Sérgio Gischkow. Tendências modernas do direito de família. Revista dos Tribunais. São Paulo, V. 628, p. 19-39, fev. 1988.

SARLET, Ingo Wolfgang. Dignidade da pessoa humana e direitos fundamentais na Constituição Federal de 1998. Porto Alegre: Livraria do Advogado, 2001

TARTUCE, Flávio, em artigo publicado em: http://jus.com.br/ $\operatorname{artigos} / 8468 /$ novos-principiosdo-direito-de-familia-brasileiro/2. 